\title{
Research on the Countermeasures of Development in Rural Home Tourism based on the Accurate Poverty Alleviation
}

\section{Fangli Li}

Haikou College of Economics, Haikou, Hainan, 570203

\author{
Keywords: Accurate Poverty Alleviation Background; Rural Tourism; Countermeasures
}

\begin{abstract}
The potentially huge economic benefits of tourism in rural areas are mainly reflected in promoting industrial upgrading in rural areas and transforming rural areas. As a result, they become the main ways and means of precision-oriented poverty alleviation. In this paper, based on the concept of precise poverty alleviation, tourism development in rural areas First of all, it analyzes the connotation and significance of accurate poverty alleviation in rural tourism, then discusses the current situation of rural tourism development in the context of precision poverty alleviation, and finally analyzes the existing problems and countermeasures in current rural tourism development.
\end{abstract}

\section{Introduction}

As early as two or three decades ago, China has initially set off the development of rural tourism industry, the development process experienced different stages of evolution, such as farmhouse music and suburban tourism. Nowadays, many rural areas have entered a higher stage of tourism development. The initial rise of rural tourism is closely related to the precise poverty alleviation in rural areas. While changing the industrial structure in rural areas, the tourism industry also plays an important role in promoting rural economic development and increasing farmers' income. Rural poverty alleviation role. As an important carrier of rural tourism, rural residential houses are an important part of supporting the development of rural tourism. Under the national policy of precise poverty alleviation, rural tourism plays an important role in strengthening the rural areas and benefiting the people, while the construction of residential and rural areas is directly related to the development of rural tourism.

\section{The precise meaning of rural tourism poverty alleviation and significance}

Accurate Poverty Alleviation in Rural Tourism is an industrial poverty alleviation method implemented in rural areas under the national precise poverty alleviation policy. The precise poverty alleviation is mainly based on the conditions of rural poverty, the number of poor people and the environment in poor areas. Ways and means to carry out targeted help and precise management of poverty alleviation targets. Accurate rural tourism poverty alleviation refers to fully tap the resource advantages of poverty-stricken areas, and actively cultivate the potential value of rural areas, the rural potential value, resource advantages and tourism, tourism to promote economic development in rural areas, and rural poor households for precision Helping to achieve the essence of poverty alleviation and poverty alleviation by precise poverty alleviation. However, in the process of specific poverty alleviation, we are not simply applying the model of precise poverty alleviation but are guided by the concept of precision poverty alleviation to realize tourism The combination of industry and pro-poor policies not only requires that rural areas in the short term be able to get rid of poverty but also to emphasize the sustainability of poverty alleviation.

\section{The significance of precision rural tourism poverty alleviation}

First of all, it is conducive to fully tap the potential value of rural areas and improve the overall quality of rural population. Rural value mainly refers to the value of production and life, ecological value and cultural value naturally assigned to the rural population. As the pace of urbanization 
accelerates, the rural value has gradually been submerged in people's perspectives. In the context of precise poverty alleviation, People will rediscover the potential value of rural society and integrate it into the meaning and fun of rural life. Second, improve rural living conditions and guide villagers to self-development. Many poor rural areas are located in areas with limited transportation, scarce population of resources and weak infrastructure, which, to a certain extent, make it more difficult to develop tourism resources. Under the policy of precise poverty alleviation of rural tourism, we will further intensify the excavation and exploitation of rural tourism resources and improve the rural living conditions and lifestyles by improving rural infrastructure and changing rural traffic conditions. This will also bring more opportunities for the economic and industrial development in rural areas. In addition, we will broaden the horizons of peasants and enhance the ability of rural areas and peasants to develop themselves through the introduction of advanced technologies and human resources. Finally, increase the income channels of peasants and innovate the mode of rural development. In rural areas, the development of rural housing, tourism, catering and processing industries will be further promoted through the development of resources in rural areas through the development of precision poverty alleviation policies so as to ensure that the economic level in rural areas will be promoted in an all-round way. In addition, Sales, restaurants and other means to participate in the construction of rural tourism, which to some extent increased the income channels of farmers to protect and improve the living standards and quality of life of farmers.

\section{The precise poverty alleviation background B \& B tourism development status quo}

Tourism refers to the residents or foreign investors of tourist destinations. Through the renovation of free houses, it provides tourists with a hotel different from the traditional hotels. The hotel buildings and facilities are highly integrated with the local customs, mainly for tourists to provide a new travel experience. This kind of bed-and-breakfast mode originally originated from the rural areas of Europe. Currently, the most common form of tourism development in our country is peasant music. The peasant music only provides simple accommodation and catering services. Therefore, it should be still in the preliminary stage of the development of tourism in our country. With the improvement of people's living standards and quality, higher demands are placed on the spiritual enjoyment of tourism. A large number of emerging and advanced B \& B tourism are emerging under the circumstance that traditional peasant music can not meet the needs of tourists.

First of all, judging from the scale of development, at present, the number of residential and residential buildings in rural areas in our country shows an increasing trend and the quality of service is constantly improving. According to the statistics from 2010 to 2015, the number of rural residential houses in the country reaches 40,000 Many, Yunnan Province, the largest number of B \& $\mathrm{B}$ in the first place. In addition, the rural bed and breakfasts and major tourism networks have also been increasing the level of cooperation, online booking B \& B to achieve more and more perfect, according to the relevant statistics show that the number of online book online booking more than 100,000 rooms, and will 2016 Compared with the same period in 2015, the number of online booking for B \& B increased by $0.6 \%$. Secondly, from the point of view of development quality, B \& B experienced the stage of development from focusing on accommodation to internal intelligent equipment. The current B \& B tourism not only provides customers with comfortable accommodation, but also enables customers to feel the rich cultural heritage. Thirdly, from the analysis of development location, the development of tourism in bed and breakfast is mainly concentrated in the areas rich in resources and convenient transportation in our country, such as Xi'an, Lijiang and Chengdu, which are based on the natural natural environment, Number or quality, all have a good level of development. Finally, from the product price point of view, most of the products are priced at the mid-level, generally maintained at 200 to 300 or so, and service personalized, distinctive home prices may be high.

\section{The precise poverty alleviation background B \& B tourism development problems}

Tourism in rural areas, as a special development industry under the precise poverty alleviation in 
rural areas, must have the corresponding rules and regulations to play the role of supervision and guidance. However, most of the current travel and accommodation tourism do not have business licenses and the government's definition of the boundary of tourism is not clear, which led to the failure of tourism in the tourism industry to guarantee the quality of service and consumer safety during the course of development. Over time and again, this chaotic and disorderly management mode can easily lead to vicious competition and lead to uneven quality of tourist services in the market. Conducive to the sustainable development of rural economy under the background of precision poverty alleviation.

The difference between rural tourism and ordinary tourism lies in the individualized service and the creative provision. The hotel and building has a strong uniqueness in site selection and decoration. However, for the long-term and stable development of the tourism in bed and breakfast, it is necessary to rely on the countryside Regional natural and cultural environment. However, from the current status quo of tourism in rural areas, there is a wide range of differences in the construction of $b$ \& $b$ accommodation in different regions or from each other. From the long-term development of tourism in B \& B, it is not conducive to the formation of brand effect and local characteristics in rural tourism.

The successful elements of the tourism development of B \& B lie in: a good geographical location, unique style, rich marketing channels, etc. However, the development of folk custom tourism in our country is relatively late and started directly from villagers' spontaneous construction and operation. However, due to the service of villagers Awareness and service professionalization of the lower ability to lead the rural tourism in the process of development, the lack of a strong sense of promotion and marketing capabilities, the current promotion methods are mainly stay online offline word of mouth in the new media and Internet economy Under the background of continuous development, if we do not grasp the online marketing methods in a timely manner, we will greatly reduce the traffic and income levels, therefore, it is not conducive to the steady and sustainable development of tourism in rural areas.

\section{The precise poverty alleviation background of tourism development in the hotel to improve measures}

Standard industry norms is to guide and constrain the development of tourism in the home and hotel direction, in order to promote the sustainable development of folk tourism, the development of uniform and standardized industry standards is an important prerequisite for the development of folk tourism, one is conducive to facilitate the government for rural tourism Industry development planning and direction, the second is to effectively guide investors in investment behavior, to further standardize the tourism development of rural areas, the market, therefore, in the industry norms must be clear responsibilities and obligations of operators, to ensure that problems arise according to.

B \& B tourism development, in addition to relying on the industry norms of the constraints and guidance, but also must have a comprehensive high-quality managers, therefore, the government must strengthen the B \& B operators operating quality and professional philosophy of training and education, and strive to improve Bed and breakfast operators awareness of service and service levels, through the introduction of advanced management techniques and concepts, and effectively develop the operator's vision. We will actively establish a rural tourism service website and fully realize the development of rural tourism network marketing so as to ensure a good online marketing platform under the mode of rural tourism sharing economy and ensure the steady development of rural tourism industry in order to achieve the objective of poverty alleviation The purpose of poverty alleviation.

Accurate Poverty Alleviation in Rural Tourism focuses on the optimization and integration of rural resources. Extending the industrial chain and optimizing the industrial structure in rural areas are the key contents of precision tourism for rural tourism. By effectively integrating the development of the primary, secondary and tertiary industries, the economy of peasants is increased Therefore, all localities should, according to local conditions, effectively implement the common 
development of tourism, agriculture, transportation, and catering industries according to local resources in rural areas. For example, Jiangxi Province has the status of "World Orange Township "reputation, so in the development of tourism in the home and accommodation at the same time, with the navel orange industry to achieve full integration, while achieving ecological picking and ecotourism industry's common development. In addition, in the process of development, we must constantly introduce various advanced technologies and strive to create high-quality and high-level tourism industry services.

First of all, the accurate identification of tourism resources and poverty in rural areas, for the development of tourism in poverty-stricken villages to record the list of poor villages in rural tourism development is the primary task of effective rural poverty reduction, because only in rural areas of actual Accurate understanding of the situation in order to make more suitable for rural poverty alleviation and development of countermeasures. Secondly, under the background of precise poverty alleviation, the main purpose of tourism development in rural areas is to get rid of poverty and get rich. Therefore, it is necessary to identify the target of poverty alleviation. First, village cadres take the lead and through mutual conversations with villagers, fully understand each household Income and poverty situation. Second, the villagers' living conditions, living standards, education and migrant workers should be considered in the form of villagers' congresses and villager congresses, and then the villagers' poverty in the village should be classified hierarchically to enhance the dynamic control of the poor and the poor, Increase their support for the development of tourism in B \& B.

\section{Conclusion}

Tourism in rural areas is a special way of alleviating poverty in rural areas under the background of precision poverty alleviation. The main purpose is to increase the income level of farmers and promote poverty alleviation in rural areas. However, influenced by the peasants' professional level and service concept, the current management concepts and marketing methods of the tourism in the rural areas are still deficient. Therefore, according to these existing problems, this article analyzes the existing problems from the aspects of the industry standard, the management idea, the marketing Ways, precise identification of poverty alleviation, optimization of industrial structure and other aspects of rural tourism development.

\section{References}

[1] Su Weiling, Zheng Yan. Study on the Development of Jinpu New District Country Bed and Breakfast in the Sight of Tourism Poverty Alleviation [J]. Foreign Trade and Economic Cooperation, 2017, (07): 69-71.

[2] Zhou Shitao. Based on the precise poverty alleviation background of rural tourism development in rural areas [J]. Rural Economy and Science, 2017,28 (13): 106-107.

[3] Lin Yun, Wu Jing. Tourism SWOT Analysis and Countermeasures of Jiangxi Rural Bed and Breakfast under the Background of Accurate Poverty Alleviation - A Case Study of Sanjalang Village, Jing'an County [J]. Zhongtu District Construction, 2017, (08): 11-14.

[4] Wu Jingnan. Study on the Realization of Precise Poverty Alleviation in Rural Tourism [J]. The Rural Economy, 2017, (03): 99-103.

[5] Tian Hui. A Probe into the Tourism Development of Rural B \& B [J]. Journal of Chongqing Institute of Electronic Engineering, 2017,26 (01): 17-20. 